\title{
Taxonomic separateness of the subspecies of Noctua interjecta Hübner (Lepidoptera: Noctuidae) inhabiting central Europe
}

\author{
Janusz Nowacki, Hanna Panagiotopoulou-Stawnicka, Robert Rutkowski \& Roman Wąsala*
}

Nowacki, J., Panagiotopoulou-Stawnicka, H., Rutkowski, R. \& Wąsala, R. 2019: Taxonomic separateness of the subspecies of Noctua interjecta Hübner (Lepidoptera: Noctuidae) inhabiting central Europe. - Entomol. Fennica 30: 33-42. https://doi.org/10.33338/ef.79904

This study focuses on morphological and genetic differences between two central European subspecies of the noctuid moth Noctua interjecta Hübner: $N$. interjecta interjecta Hübner, 1803 from Transcarpathia in Ukraine and $N$. interjecta caliginosa (Schawerda, 1919) from Poland. While the morphological differences between these taxa are fairly obvious, individuals from these two populations were found to differ also genetically, as indicated by the cytochrome $\mathrm{c}$ oxidase I (COI) gene sequences. The Transcarpathian population exhibits solely the NImizH3 haplotype, but the Polish one the relatively distant NImizH1 and NImizH2 haplotypes. A Neighbour-Joining tree and a network of haplotypes separated the two haplotypes found in Poland (N. i. caliginosa) from those derived from NImizH3 ( $N$. i. interjecta). The divergence time for these two groups was estimated as 400-600 thousand years before present, coinciding with the maximum extent of the Pleistocene ice-sheet covering Europe.

J. Nowacki \& R. Wasala, Department of Entomology and Environmental Protection, Poznań University of Life Sciences, ul. Dąbrowskiego 159, 60-594 Poznań, Poland.E-mails: janusz.nowacki@up.poznan.pl; * Corresponding author: roman.wasala@up.poznan.pl

H. Panagiotopoulou-Stawnicka \& R. Rutkowski, Museum and Institute of Zoology PAS, ul.Wilcza 64,00-679 Warsaw, Poland; E-mails: hpana@miiz.waw.pl, robertrut@miiz.waw.pl

Received 8 January 2018, accepted 1 June 2018

\section{Introduction}

Noctua interjecta Hübner, 1803 is a moth species of the family Noctuidae with an Atlantic-Mediterranean distribution. It currently occurs from the Iberian Peninsula across the whole of western and southern Europe reaching the Baltic Sea in the north (Fibiger 1993, Nowacki 1998, Aarvik et al. 2017). Only the nominative subspecies $N$. interjecta interjecta Hübner, 1803 is found in the southern part of its range, being distributed from Spain and Portugal across southern and central France, south of the Alps across Italy and the Balkan Peninsula as far as Bulgaria. Noctua interjecta interjecta is also found in central Europe south of the Sudetens and Carpathians, i.e. in Slovakia, Hungary, Romania and Transcarpathia in Ukraine.

In contrast, the subspecies $N$. interjecta caliginosa (Schawerda, 1919) is found in the north- 
ern part of the species' range, from western France and the U. K. through Belgium, the Netherlands, Denmark, Norway and Germany to the countries around the Baltic Sea, i.e. southern Sweden and Finland, western and northern Poland, and also Lithuania, Latvia and Estonia (Aarvik et al. 2017).

Before the end of the $20^{\text {th }}$ century, the only Polish records of $N$. interjecta were from a few localities in the west of the country, from the Baltic coast as far south as Lower Silesia (Nowacki 1994). These moths represented N. i. caliginosa. The last 30 years, however, have witnessed a rapid eastward expansion of the species within Poland and in other countries around the Baltic. It has been recorded in numerous localities from north-eastern Poland through central Wielkopolska (Greater Poland) to Upper Silesia (Blaik et al. 2009). In 2014, a single specimen of $N$. interjecta was trapped for the first time in the Bieszczady Mts. in south-eastern Poland (Nowacki \& Pałka 2015). It is worth emphasising that, judging by its external appearance, this specimen undoubtedly belonged to the subspecies $N$. $i$. interjecta. Hence, this is currently the northernmost locality of this southern form of $N$. interjecta in the eastern part of its central European range. Consequently, both subspecies of $N$. interjecta are found in Poland, albeit in localities separated from one another.

This paper examines the hypothesis that the two central European subspecies of $N$. interjecta, at present occurring as geographically isolated populations and exhibiting marked morphological differences, are also genetically distinct. This may be the result of the originally contiguous range in Europe having become disjunct in the past. The molecular analysis is based on $N$. $i$. caliginosa from western Poland and $N$. i. interjecta from the Transcarpathian region of Ukraine.

The situation is intriguing as, in addition to the expansion of $N$. i. caliginosa, also $N$. $i$. interjecta is expanding northwards within central Europe (Nowacki \& Pałka 2015, Bálint et al. 2016,). It is therefore highly likely that the ranges of these two subspecies will eventually overlap. As a consequence, gene pools of the two subspecies may merge, eventually leading to disappearance of the two separate taxa.

\section{Materials and methods}

For the molecular research, adults of both subspecies of $N$. interjecta, was accumulated between 2009 and 2017 during fieldwork carried out at

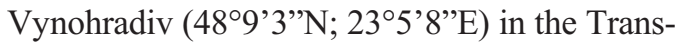
carpathian region of Ukraine, and from 2000 to 2017 in western Poland at the following localities: Mrzeżyno (54ㅇ' $11^{\prime \prime} \mathrm{N}$; $\left.15^{\circ} 16^{\prime} 45^{\prime \prime} \mathrm{E}\right)$, Drawsko Pomorskie (533 ' $45^{\prime \prime} \mathrm{N}$; $\left.15^{\circ} 48^{\prime} 24^{\prime \prime} \mathrm{E}\right)$, Unieście (5416'14’N; 16 ${ }^{\circ} 5^{\prime} 42^{\prime}$ 'E), Potrzebowice (52 $51^{\prime} 5^{\prime}$ 'N; 16 $\left.6^{\circ} 9^{\prime} 53^{\prime \prime} \mathrm{E}\right)$ and Poznań $\left(52^{\circ} 24^{\prime} 28^{\prime \prime} \mathrm{N} ; 16^{\circ} 51^{\prime} 38^{\prime \prime} \mathrm{E}\right)$. The moths were attracted at night to a white screen illuminated by a $250 \mathrm{~W}$ mercury vapour lamp. The individuals were picked off the screen and placed in test tubes containing ethanol:

- Noctua interjecta interjecta: 5 exx. Vynohradiv, Transcarpathia, Ukraine, 3.-5.VIII. 2016,

- Noctua interjecta caliginosa: 3 exx. Mrzeżyno, Poland, 12.VIII.2016; 1 ex. Drawsko Pomorskie, Poland, 10.VIII.2016; 1 ex. Poznań, Poland, 13.VIII.2016.

For the morphological analysis, a larger sample of the moths from both subspecies was trapped at Vynohradiv, Transcarpathia, Ukraine (N. i. interjecta) and Drawsko Pomorskie, Mrzeżyno, Unieście, Potrzebowice and Poznań in western Poland (N. i. caliginosa).

\subsection{Morphological analysis}

The spans and colouration of both pairs of wings were compared in ten individuals from each subspecies. The genitalia of five males and five females of each subspecies were also studied. The genitalia preparations were made according to the method described by Nowacki (1995).

\subsection{Laboratory procedures}

DNA extractions from a single leg were performed using a NucleoSpin Tissue Kit (MACHEREY-NAGEL, distribution in Poland by AQUA LAB) in line with the standard proto- 
col. For taxonomic identification a 658 bp region near the 5' end of the mitochondrial cytochrome $\mathrm{c}$ oxidase I (COI) gene was amplified with the primers LEPF1 5'-ATTCAACCAATCATAAAGATATTGG and LEPR1 5'-TAAACTTCTGGATGTCCAAAAAATCA (deWaard et al. 2008, Hausmann et al. 2011). The amplified fragment includes the region regarded as the standard barcode for the animal kingdom (Hebert et al. 2003).

PCR reactions were performed in $30 \mu 1$ of reaction mix containing $1 \times$ REDTaq ${ }^{\circledR}$ ReadyMix $^{\mathrm{TM}}$ PCR Reaction Mix (Sigma-Aldrich, Darmstadt, Germany), $0.2 \mu \mathrm{M}$ of each primer and $1.5 \mu \mathrm{l}$ of the extracted DNA. The amplification conditions were as follows: initial denaturation for $3 \mathrm{~min}$ at $94^{\circ} \mathrm{C}$, followed by 40 cycles for $30 \mathrm{~s}$ at $94^{\circ} \mathrm{C}, 30 \mathrm{~s}$ at $55^{\circ} \mathrm{C}$ and $1 \mathrm{~min}$ at $72^{\circ} \mathrm{C}$, ending in a final extension step of $5 \mathrm{~min}$ at $72{ }^{\circ} \mathrm{C}$. The Exo-SAP clean-up protocol was used for enzymatic purification of the amplified products. The reactions were performed by adding $0.025 \mu \mathrm{l}$ Exonuclease I (20 U/ $\mu 1), 0.25 \mu$ l Shrimp Alkaline

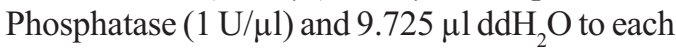
of the PCR products, followed by incubation of the samples at $37^{\circ} \mathrm{C}$ for $30 \mathrm{~min}$ and $95^{\circ} \mathrm{C}$ for 5 min.

The purified PCR products were sequenced on the Applied Biosystems ${ }^{\circledR}$ ABI $3500 x L$ Genetic Analyzer platform (Applied Biosystems, Foster City, USA). The resulting DNA chromatograms were analysed and aligned using BioEdit software v.7.0.5.3 (Hall 1999). Although the designed primers amplified a fragment of about 658 base pairs in length, only 600 base pairs were clearly readable in all the samples.

\subsection{Statistical analysis}

The number of haplotypes $(\mathrm{H})$, haplotype diversity $(\mathrm{h})$, nucleotide diversity $(\pi)$ and mean number of nucleotide differences among the haplotypes $(\mathrm{k})$ in the overall sample and in particular populations were calculated using DNAsp 5.10 (Librado \& Rozas 2009). ARLEQUIN v3.5.1.2 (Excoffier \& Lischer 2010) was used to identify unique haplotypes. The genetic distance among haplotypes was calculated using the uncorrected proportional distance ( $\mathrm{p}$-distance) in
MEGA version 5 (Tamura et al. 2011). A median-joining haplotype network (Bandelt et al. 1999) was constructed in NETWORK v4.6.1.1 (Fluxus Technology Ltd.). In addition, a neighbour-joining tree was inferred. We used a Tamura 3-parameter substitution model, chosen according to the Bayesian Information Criterion using ModelGenerator v0.85 (Keane et al. 2006). The COI sequence of $N$. janthe (Borkhausen, 1792) (KX045227, Mutanen et al. 2016) was used as an outgroup. Finally, the haplotypes identified in this study were compared with homologous sequences of $N$. interjecta from GenBank (https:// www.ncbi.nlm.nih.gov/gen bank).

Divergence times were estimated using the 600 bp COI gene in Beast V. 1.7.5 (Drummond et al. 2012). The $\mathrm{HKY}+\mathrm{G}$ model was implemented, and the three codon positions were unlinked in order to be estimated independently. As there are no fossil records of reasonably closely related species that can be used to calibrate the tree topologies for this study, we used two conventional mutation rates for the arthropod mitochondrial COI gene taken from the literature: $2.3 \%$ (originally proposed by Brower (1994), with similar rates later independently found in other insects; see below) and 1.5\% (Farrell 2001, Quek et al. 2004) per million years (per My). BEAST analyses were carried out according to either a strict or a lognormal relaxed clock so as to study the effect of these two clock models on the resulting estimates of divergence times.

According to the strict clock model, we fixed a rate of 0.0115 or 0.0075 substitutions $/$ site/million years (corresponding to a divergence rate of $2.3 \%$ or $1.5 \%$ per million years, respectively). For the lognormal relaxed clock model, we assumed a normal distribution with a mean of 0.0115 or 0.0075 , and set the standard deviation at $10 \%$.

A Yule speciation process model was selected for the tree prior, with a 50\% majority-rule consensus tree obtained from Bayesian analysis of the combined molecular and morphological dataset as the input topology. Two independent MCMC analyses were run for 10,000,000 generations, with Markov chains sampled every 1,000 generations. The analysis results of the two runs were combined in LogCombiner v1.7.5 with the initial $10 \%$ of the trees discarded as burn-in. 

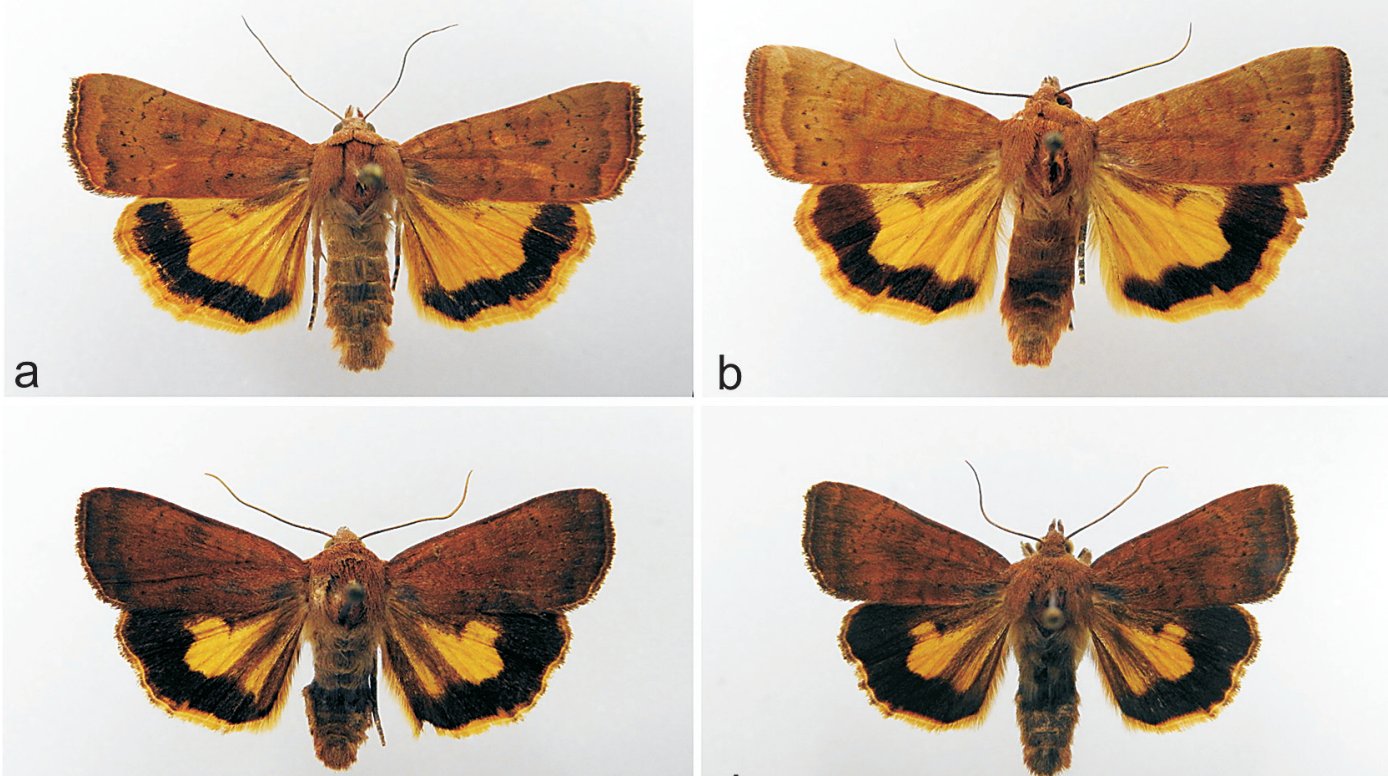

C

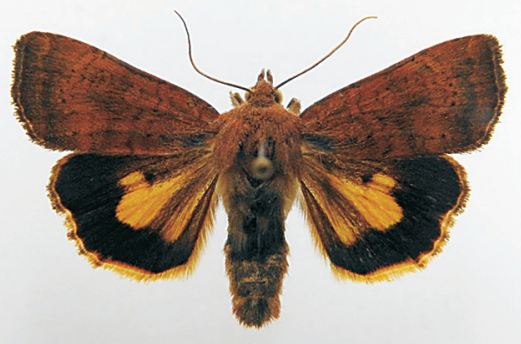

Fig. 1. - a, b. Noctua interjecta interjecta Hübner, 1803 from Vynohradiv, Transcarpathia, Ukraine, 13.VII.2010 (a) and Vynohradiv, Transcarpathia, Ukraine, 4.VIII.2016 (b). - c, d. Noctua i. caliginosa (Schawerda, 1919) from Unieście, Poland, 2.VIII.2000 (c) and Potrzebowice, Poland, 1.VIII.2008 (d).

Tracer V. 1.5 (Rambaut \& Drummond 2007) was used to determine convergence, measure the effective sample size of each parameter, and calculate the mean and $95 \%$ highest posterior density (HPD) intervals for divergence times. The consensus tree was compiled with TreeAnnotator 1.7.5 and displayed in FigTree V. 1.4.0. In addition, Bayes factors (Kass \& Raftery 1995) were calculated using log marginal likelihood with stepping stone sampling for a comparison of the best fit model between the strict and lognormal relaxed clock.

\section{Results}

\subsection{Morphology}

The forewings of $N$. i. interjecta from Transcarpathia in Ukraine have a pale tawny ground colour with a faint pattern. The barely visible kidney-mark and oval are of the same hue as the wing ground colour, intermittently edged dark brown. The outermost, wavy, cross-line is somewhat darker than the ground colour, while the central cross-lines are broken, faint, here and there highlighted by black scales. The hindwings are yellow with quite a broad black border following the outer edge (Fig. 1a, b). The wingspan is $36-38 \mathrm{~mm}$.

Noctua interjecta caliginosa from northwestern Poland differs substantially in appearance from the nominative form. The forewing ground colour is much darker - dark reddish brown, becoming somewhat paler nearer the wing base; the pattern is barely visible. The kidney-mark and the oval are difficult to make out; they are of the same hue as the ground colour, and only here and there delicately outlined in dark brown. The outermost, wavy cross-line is darker, almost black, and contrasts with the ground colour. The other cross-lines are faint, sometimes picked out in a darker brown, which makes them somewhat better visible. The yellow-centred hindwings have a very broad black border (much broader than in $N$. $i$. interjecta) following the outer edge of the wing and covering much of the wing area (Fig. 1c, d). The wingspan is $32-36$ $\mathrm{mm}$.

Inspection of the genitalia revealed no structural differences between the two subspecies in either males or females (Figs 2, 3). 
a
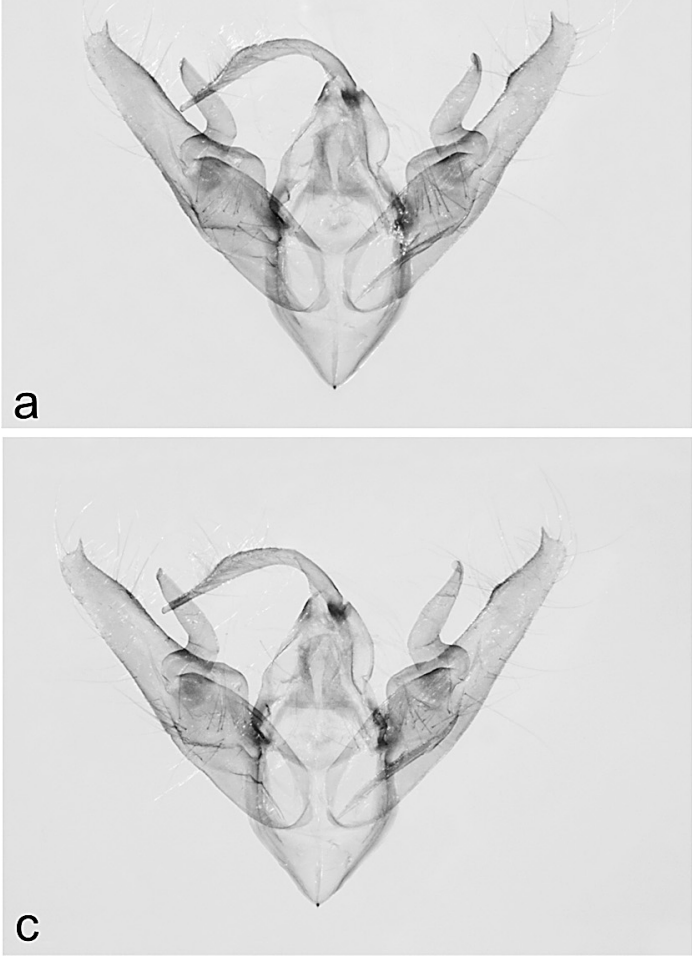

b
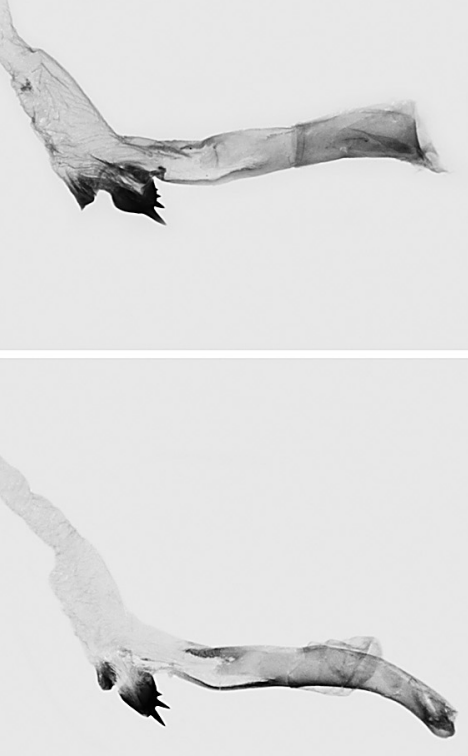

Fig. 2. Noctua interjecta male genitalia. - a, b. N. i. interjecta, Vynohradiv, Transcarpathia, Ukraine, 4.VII.2016. - c, d. N. i. caliginosa, Mrzeżyno, Poland, 18.VII.2014.

\subsection{Genetic analysis}

A 600 base pair long fragment of the cytochrome oxidase subunit 1 (COI) for 10 specimens of $N$. interjecta from Poland and Ukraine was analysed: 6 polymorphic sites were found within this fragment (4 parsimony-informative sites). All variable sites represented transitions. The base composition was as follows: A $-16.67 \%, \mathrm{C}-$ $46.67 \%, \mathrm{~T}-20.00 \%, \mathrm{G}-16.67 \%$.

Three haplotypes were identified among the 10 sequences obtained. The NImizH1 haplotype (GenBank Acc. No: MH172470) proved to be clearly dominant in terms of its frequency of occurrence in Poland, being found in four out of five individuals from Mrzeżyno and Drawsko Pomorskie (Poland). Only one haplotype NImizH3 (GenBank Acc. No: MH172472) - was found in five Ukrainian samples from Vynohradiv (Transcarpathia). The NImizH2 haplotype (GenBank Acc. No: MH172471) was found in just one sample from Poland (Poznań). There were five substitutions separating NImizH1 from NImizH3 (p-distance $=0.7 \%$ ) and two separating $\mathrm{NImizH} 1$ from NImizH2 $(\mathrm{p}$-distance $=0.3 \%$ ) (Fig. 4). The mean genetic distance between the 'Polish" haplotype group and NImizH3 was $0.8 \%$. Overall haplotype diversity was $0.644 \pm$ 0.101 with an associated nucleotide diversity of 0.00437 . The average number of nucleotide differences among the haplotypes (k) was 2.622.

The haplotypes identified in this study were compared with homologous sequences of $N$. interjecta from GenBank (https://www.ncbi.nlm. nih.gov/gen bank) (Table 1). The comparison revealed seven haplotypes. Two of the haplotypes identified in this study (NimizH1 and NImizH3) matched sequences from GenBank. Aside from Poland, NImizH1 was found only in Germany, whereas the Ukrainian NImizH3 also turned up in the Netherlands, the U.K. and France (Fig. 4, Table 1). The fragment amplified in this study was shorter than the sequences deposited in GenBank. Hence, some polymorphic sites are 


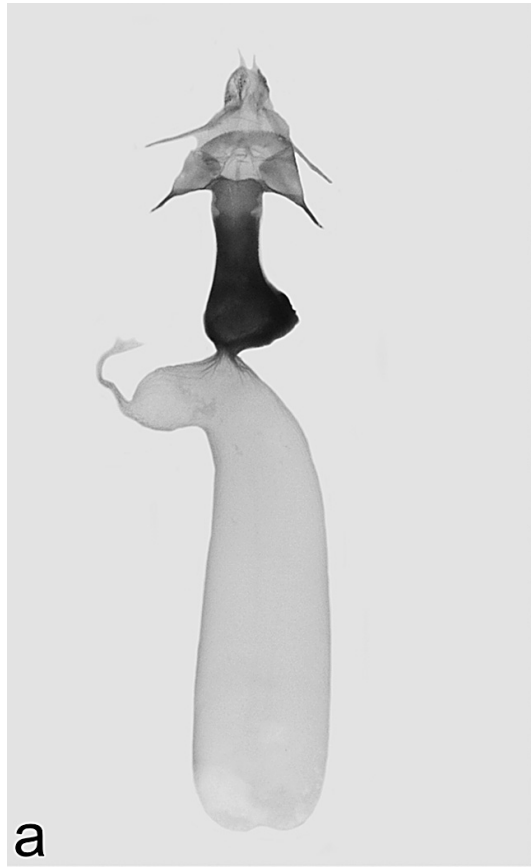

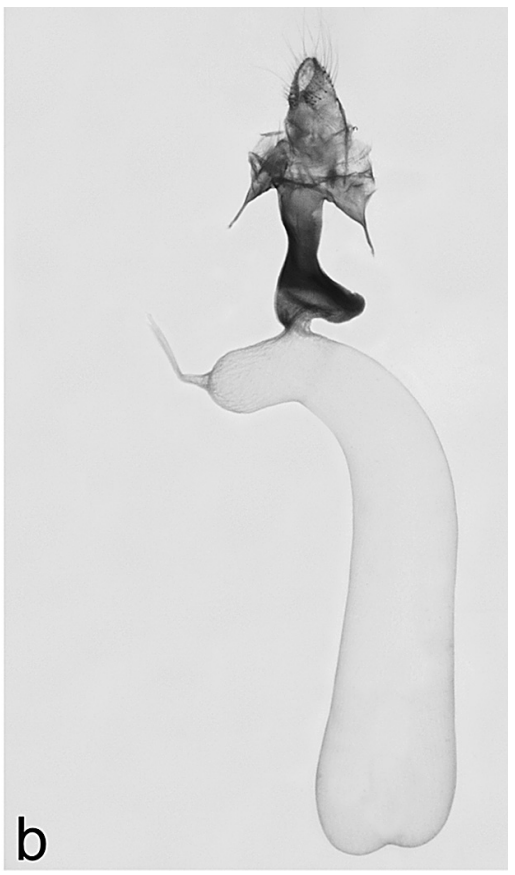

Fig. 3. Noctua interjecta female genitalia. $-a$. N. i. interjecta, Vynohradiv, Transcarpathia, Ukraine, 20.VII.2017. - b. Noctua i. caliginosa, Poznań, Poland, 13.VIII.2016. missing from the present comparison, namely, the sequences HM914226 and KX041259 from Germany, indicated by NImizH1 in this comparison; these are two different haplotypes based on the alignment of a longer ( $658 \mathrm{bp}$ ) fragment. The number of base differences per site ( $\mathrm{p}$-distance) between sequences did not exceed $1.5 \%$.
The Neighbour-Joining tree (Fig. 5) yielded a similar topology to the haplotype network. Again, two groups of haplotypes were indicated, one comprising haplotypes from Poland and $\mathrm{NIgbH5}$, the other containing haplotypes grouped around NImizH3. Likewise, an identical topology was obtained with Bayesian analysis in

Table 1. Homologous sequences of Noctua interjecta from GenBank used in comparison with NImiz haplotypes identified in this study. Acc. number - GenBank accession number.

$$
\text { Acc. number Locality }
$$

Haplotype

\section{Hausmann et al. 2011:}

HM914226

JF415611 HQ563547

Mutanen et al. 2016:

KX044477

KX047693

KX043153

KX043111

KX047097

KX041259

KX044916

KX048851

$\mathrm{KX} 043926$
Germany: Bavaria, Oberbayern, Ruhpolding, Roethelmoos Germany: Bavaria, Upper Bavaria, Mue-Obermenzing, ZSM Germany: Bavaria, Oberpfalz, Neustadt a.d. Waldnaab, Schwarzenbach, Parkstein-Huetten

France: Haute Normandie, Seine Maritime, Doudeville Netherlands: South Holland, Wassenaar United Kingdom: England, Essex, Caston United Kingdom: England, Norfolk, Gait Barrows France: Haute Normandie, Seine Maritime, Varengeville sur Mer, Bois des communes

Germany: Saxony, Zittau

France: Haute Normandie, Eure, Fatouville Grestain Netherlands: South Holland, Wassenaar

United Kingdom: England, Hertfordshire, Sawbridgeworth, Sawbridgeworth Marsh
NImizH1

$\mathrm{NIgbH} 4$

$\mathrm{NIgbH} 7$

$\mathrm{NIgbH} 4$

$\mathrm{NImizH} 3$

$\mathrm{NImizH3}$

$\mathrm{NImizH} 3$

$\mathrm{NImizH3}$

NImizH1

$\mathrm{NImizH} 3$

$\mathrm{NIgbH} 5$

NIgbH6 
Fig. 4. Median-joining haplotype network of Noctua interjecta, based on 600 bp sequences identified in this study (NImiz) and GenBank (Nlgb) haplotypes. The size of a circle is approximately proportional to the frequency of occurrence of the given haplotype in the set of 22 sequences. The pie charts show the proportions of the haplotypes that occur in different countries in the studied set of 22 sequences.

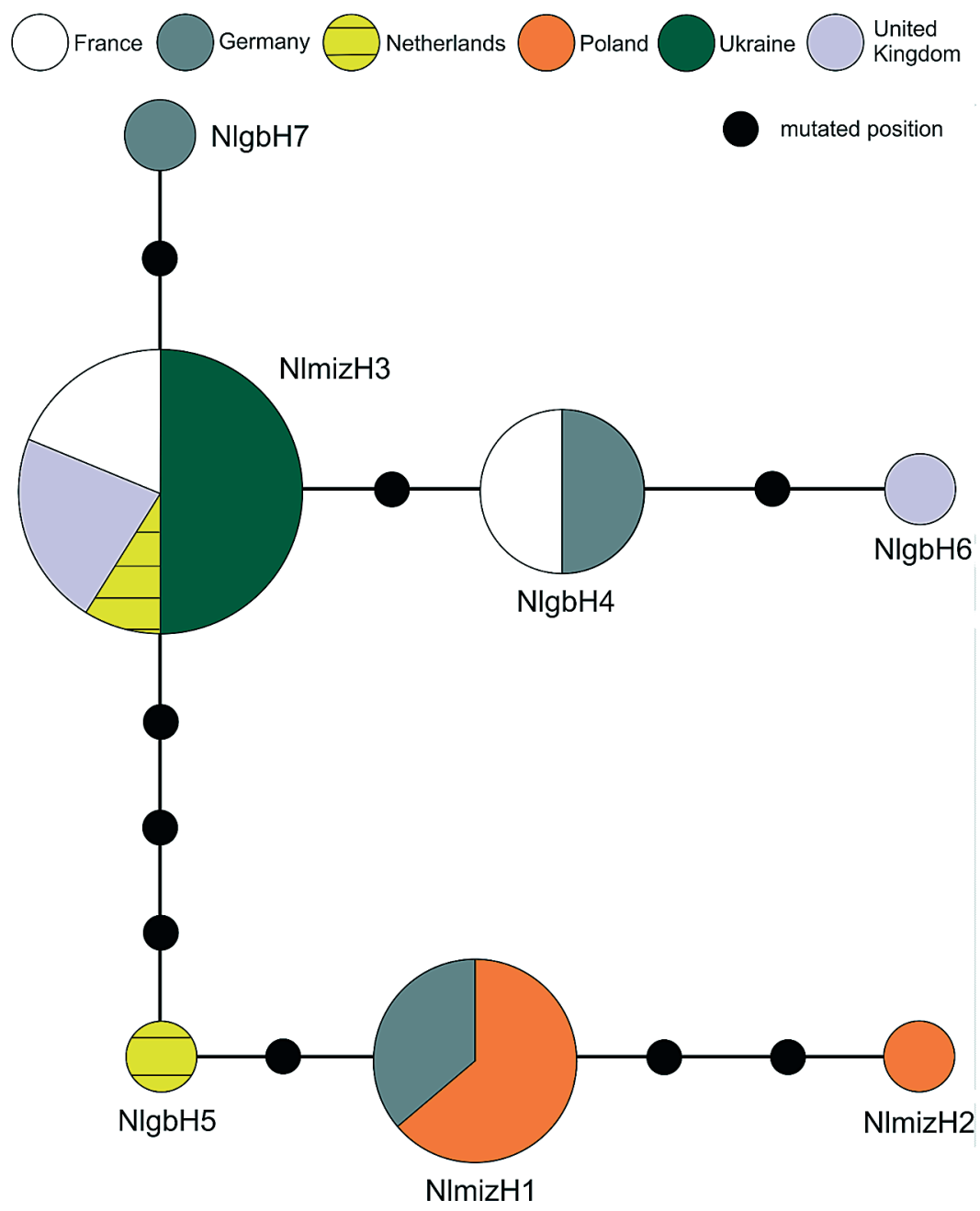

BEAST (tree not shown). The median divergence time for NImizH1 and NImizH2 was $0.0950 \mathrm{My}$ [95\% HPD 0.0049-0.2803] and 0.0388 My [95\% HPD $0.0012-0.1323$ ] for the $1.5 \%$ and $2.3 \%$ mutation rates, respectively. The divergence times between the "Polish" haplotypes and the haplotypes originating from NImizH3 were $0.6397 \mathrm{My}$ [95\% HPD 0.2414-1.2015] and 0.4192 [95\% HPD 0.1571-0.7843] for the $1.5 \%$ and $2.3 \% \mathrm{mu}-$ tation rates, respectively.

\section{Discussion}

Morphological analysis of $N$. interjecta individuals representing populations from two different regions of Europe separated by a distance of around $1,000 \mathrm{~km}$ showed that $N$. interjecta interjecta from Transcarpathia in Ukraine differed distinctly in wingspan and wing ground colouration from $N$. interjecta caliginosa trapped in western Poland. Individuals with intermediate features were not found in either population of the two subspecies. Both male and female genitalia of the two subspecies were identical. Hence, there should be no morphological barriers to hybridization between these two populations.

Genetic analysis showed that $N$. i. interjecta from Transcarpathia in Ukraine, where only the NImizH3 haplotype was found, differs distinctly in this respect from N. i. caliginosa from Poland, in which the NImizH1 haplotype was predominant. Nevertheless, this is quite a small genetic distance, less than $1 \%$. In general, it is recom- 


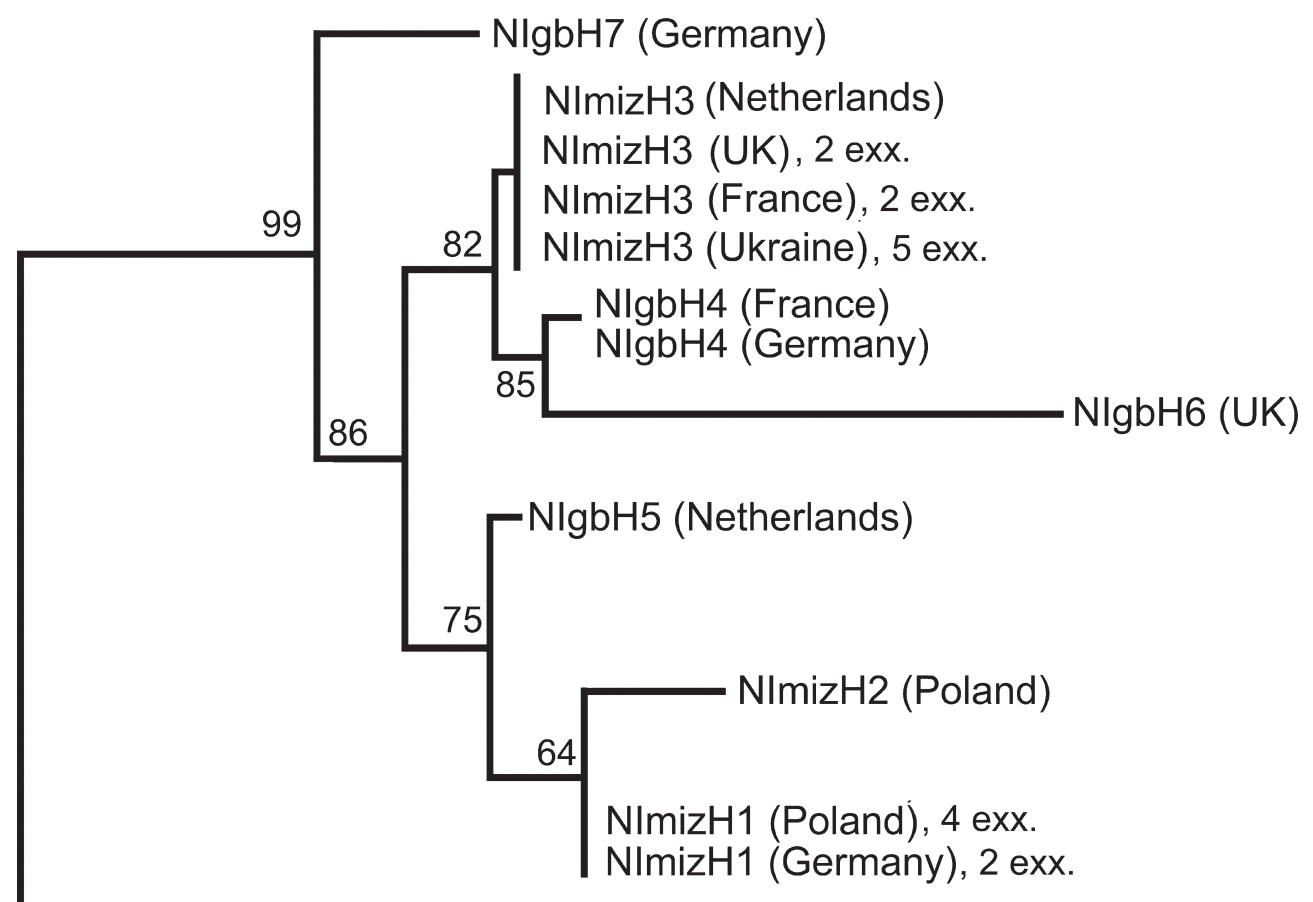

0.005

\section{N. janthe}

Fig. 5. Evolutionary relationships of $\mathrm{COI}$ haplotypes (600 bp) of Noctua interjecta estimated using the Neighbour-Joining method. The haplotypes identified in this study are preceded by NImiz, haplotypes from GenBank by NIgb. The bootstrap consensus tree was inferred from 1,000 replicates. The percentage of replicate trees in which the associated taxa clustered together in the bootstrap test (1,000 replicates) are shown next to the branches. The tree is drawn to scale, with branch lengths in the same units as those of the evolutionary distances used to infer the phylogenetic tree. The evolutionary distances were computed using the Tamura 3-parameter method (Tamura 1992) and are given in the units of the number of base substitutions per site. The $\mathrm{COI}$ sequence of $N$. janthe (KX045227) was used as an outgroup.

mended that interspecies genetic distance, calculated based on COI sequence, should be higher or equal than $2 \%$, whereas within-species diversity of COI should not exceed 2\% (Hebert et al. 2003; Ball et al. 2005). Hence, the level of differentiation, found in this study, clearly reflects withinspecies genetic diversity. Surprisingly, however, comparison of our results with the haplotype sequences of $N$. interjecta from other parts of Europe (Hausmann et al. 2011, Mutanen et al. 2016) shows that the Ukrainian population has genetically far more in common with the populations in western Europe (France, the Netherlands, the U.K.) than with the Polish populations (Fig. 4).

The results of this research, together with data from the GenBank listed in Table 1 and illustrated as a median-joining haplotype network and phylogenetic tree in Figs. 4 and 5, indicate that the NImizH3 haplotype is widespread and characteristic of $N$. $i$. interjecta, whereas the NImizH1 haplotype found in Poland and eastern Germany is typical of $N$. i. caliginosa. These results confirm the hypothesis regarding the phylogeny and interrelationships of the two subspecies of $N$. interjecta, which assumes that the division into two subspecies took place when the species' original contiguous range in Europe broke up, giving rise to the subsequent long isolation of the two populations. The genetic analysis suggests that this breakup may have occurred between 640 and 420 thousand years ago.

Obviously, the precision of genetic dating 
(estimating the time of divergence between genes or species based on DNA sequences) depends closely on molecular clock calibration (Roger \& Hug 2006). Unfortunately, case-specific parameters underlying the calibration are rarely available, so they have to be replaced by some universal estimates. As a result, molecular-based estimates of divergence times frequently do not match expectations from non-molecular data (Hedges \& Kumar 2004). Such discrepancies have raised a number of controversies about divergence time estimates recovered from molecular studies (Hug \& Roger 2007).

The universal mutation rate of COI was also used in this analysis: hence, the results only roughly reflect the age of divergence between the two groups of haplotypes and should be interpreted with caution. Nonetheless, the approximate time of divergence seems to correspond well with the glaciation history of the continent. The range disruption could have come about during the Pleistocene as a result of the San (southern Poland) or Elster (Germany) glaciation some 500 thousand years ago, when the large part of Europe, including the whole territory of the contemporary Poland, became submerged under an icesheet. The remainder of the continent, from the Pyrenees to the Black Sea, belonged to the periglacial zone with permafrost (Mojski 1993).

Consequently, the following phylogeographic scenario appears likely for $N$. interjecta. The species may have been able to survive in two refugia - the Pyrenean one along the Atlantic coast, and the near-eastern one to the south of the Black Sea. It should thus have been during the glacial period that the two subspecies $N$. $i$. interjecta and $N$. i. caliginosa diverged. Once the ice-sheet had receded from Europe in the Holocene, both subspecies began to spread northwards. Noctua interjecta caliginosa with the NImizH1 haplotype, adapted to the Atlantic climate, moved primarily up the coasts of the Atlantic Ocean and North Sea, thereafter gradually expanding eastwards to Germany and Poland.

Noctua interjecta interjecta, which came into being in the near-eastern refuge, very probably with the dominant NImizH3 haplotype and adapted to the warmer Mediterranean climate, was most likely extending its range gradually westwards along the coasts of the Mediterranean
Sea as early as the early Holocene. This subspecies must have occurred during most of the Holocene in a contiguous distribution in Europe south of the line of central European mountains, i.e. the Carpathians, Sudetens and Alps, and also the highest mountain ranges in the Balkans. The meeting of the two subspecies in western Europe led to formation of populations with admixture of haplotypes, characteristic of both subspecies, which are currently found in the Netherlands and south-west Germany.

At this time, however, $N$. i. caliginosa with the NImizH1 haplotype was already present much farther to the east in Germany and Poland. The climate in these countries, and also along the Atlantic and North Sea coasts, is cooler and too severe for the Mediterranean $N$. i. interjecta, which has prevented the latter from colonising those regions. In this way we can explain that the population of $N$. i. caliginosa with the dominant NImizH1 haplotype occurs in Poland. The NImizH2 haplotype, derived from NImizH1 probably later on, and currently it has not been found in western European populations. However, analysing the distribution of the subspecies in Western Europe is beyond the scope of the present paper, and awaits for accumulation of respective data.

\section{References}

Aarvik, L., Bengtsson, B., Elven, H., Ivinskis, P., Jürivete, U., Karsholt, O., Mutanen, M. \& Savenkov, N. 2017: Nordic-Baltic Checklist of Lepidoptera. - Norwegian Journal of Entomology. Supplement 3. 236 pp.

Ball, S. L., Hebert, P. D. N., Burian, S. K. \& Webb, J. M. 2005: Biological identifications of mayflies (Ephemeroptera) using DNA barcodes. - Journal of the North American Benthological Society 24: 508-524. doi: https://doi.org/10.1899/04-142.1

Bálint, Z., Katona, G. \& Ronkay, L. 2016: Data to the knowledge of the Macrolepidoptera fauna of the Sălajregion, Transylwania, Romania (Arthropoda: Insecta). - Studia Universitatis "Vasile Goldis", Seria Stiintele Vietii 26, Supplement 1: 59-74.

Bandelt, H.-J., Forster, P. \& Röhl, A. 1999: Median-joining networks for inferring intraspecific phylogenies. - Molecular Biology and Evolution 16: 37-48. doi: https://doi.org/10.1093/oxfordjournals.molbev. a026036

Blaik, T., Malkiewicz, A. \& Dobrzański, X. 2009: The expansion of Noctua interjecta Hübner, [1803] (Lepidoptera: Noctuidae) in southwestern Poland in the ye- 
ars 2001-2009. - Acta entomologica silesiana 17: 19-23. [In Polish.]

Brower, A. V. Z. 1994: Rapid morphological radiation and convergence among races of the butterfly Heliconius erato inferred from patterns of mitochondrial DNA evolution. - Proceedings of the National Academy of Sciences of the United States of America 91: 64916495. doi: https://doi.org/10.1073/pnas.91.14.6491

deWaard, J. R., Ivanova, N. V., Hajibabaei, M. \& Hebert, P. D. N. 2008: Assembling DNA barcodes: analytical protocols: - In: Martin, C. (ed.), Methods in molecular biology: environmental genetics: 275-293. Humana Press, Totowa, New York.

Drummond, A. J., Suchard, M. A., Xie, D. \& Rambaut, A. 2012: Bayesian phylogenetics with BEAUti and the BEAST 1.7. - Molecular Biology and Evolution 29: 1969-1973. doi: https://doi.org/10.1093/molbev/ mss075

Excoffier, L. \& Lischer, H. E. L. 2010: Arlequin suite ver 3.5: a new series of programs to perform population genetics analyses under Linux and Windows. - Molecular Ecology Resources 10: 564-567. doi: https://doi.org/10.1111/j.1755-0998.2010.02847.x

Farrell, B. D. 2001: Evolutionary assembly of the milkweed fauna: cytochrome oxidase I and the age of Tetraopes beetles. - Molecular Phylogenetics and Evolution 18: 467-478. doi: https://doi.org/10.1006/ mpev. 2000.0888

Fibiger, M. 1993: Noctuidae Europaeae vol. 2. Noctuinae II. - Entomological Press, Sorø, Denmark. 230 pp.

Fluxus Technology Ltd.: http://www.fluxus-engineering.com (Site visited on 17 May 2018).

Hall, T. A. 1999: BioEdit: a user-friendly biological sequence alignment editor and analysis program for Windows 95/98/NT. — Nucleic Acids Symposium Series 41: 95-98.

Hausmann, A., Haszprunar, G., Segerer, A. H., Speidel, W., Behounek, G. \& Hebert, P. D. N. 2011: Now DNA-barcoded: The butterflies and larger moths of Germany. - Spixiana 34(1): 47-58.

Hebert, P. D. N., Cywinska, A., Ball, S. L. \& deWaard, J. R. 2003: Biological identifications through DNA barcodes. - Proceedings of the Royal Society of London B 270: 313-321. doi: https://doi.org/10.1098/rspb. 2002.2218

Hedges, S. B. \& Kumar, S. 2004: Precision of molecular time estimates. - Trends in Genetics 20(5): 242-247. doi: https://doi.org/10.1016/j.tig.2004.03.004

Hug, L. A. \& Roger, A. J. 2007: The impact of fossils and taxon sampling on ancient molecular dating analyses. - Molecular Biology and Evolution 24(8): 18891897. doi: https://doi.org/10.1093/molbev/msm115

Kass, R. E. \& Raftery, A. E. 1995: Bayes factors. — Journal of the American Statistical Association 90: 773795. doi: https://doi.org/10.1080/01621459.1995. 10476572

Keane, T. M., Creevey, C. J., Pentony, M. M., Naughton, T. J. \& McInerney, J. O. 2006: Assessment of methods for amino acid matrix selection and their use on empirical data shows that ad hoc assumptions for choice of matrix are not justified. - BMC Evolutionary Biology 6: 29. doi: https://doi.org/10.1186/1471-2148-629

Librado, P. \& Rozas, J. 2009: DNASP v5: A software for comprehensive analysis of DNA polymorphism data. —Bioinformatics 25: 1451-1452. doi: https://doi.org/ 10.1093/bioinformatics/btp187

Mojski, J. E. 1993: Europa w Plejstocenie, ewolucja środowiska przyrodniczego. - Wydawnictwo PAE. Warszawa. 333 pp. [In Polish.]

Mutanen, M., Kivelä, S. M., Vos, R. A., Doorenweerd, C., Ratnasingham, S., Hausmann, A., Huemer, P., Dinca, V., van Nieukerken, E. J., Lopez-Vaamonde, C., Vila, R., Aarvik, L., Decaens, T., Efetov, K. A., Hebert, P. D., Johnsen, A., Karsholt, O., Pentinsaari, M., Rougerie, R., Segerer, A., Tarmann, G., Zahiri, R. \& Godfray, H. C. 2016: Species-level para- and polyphyly in DNA barcode gene trees: Strong operational bias in European Lepidoptera. - Systematic Biology 65(6): 1024-1040. doi: https://doi.org/10.1093/sysbio/ syw044

Nowacki, J. 1994: Structure of distribution ranges of noctuid moths Lepidoptera, Noctuidae in coastal dunes belt of Polish Baltic Shore. - Wiadomości Entomologiczne 12. Supplement. 127 pp. [In Polish.]

Nowacki, J. 1995: Preparation on internal parts of Lepidopteran copulatory organs, as exemplified by the noctuids (Lepidoptera, Noctuidae). - Wiadomości Entomologiczne 14: 113-117. [In Polish.]

Nowacki, J. 1998: The noctuids (Lepidoptera, Noctuidae) of Central Europe. - Bratislava. 143 pp.

Nowacki, J. \& Pałka, K. 2015: New data on the occurrence of Noctua interjecta (HÜBNER, 1803) (Lepidoptera, Noctuidae) in Poland. - Wiadomości Entomologiczne 34(3): 76-77. [In Polish.]

Quek, S. P., Davies, S. J., Itino, T. \& Pierce, N. E. 2004: Codiversification in an ant-plant mutualism: stem texture and the evolution of host use in Crematogaster (Formicidae: Myrmicinae) inhabitants of Macaranga (Euphorbiaceae). - Evolution 58: 554-570. doi: https://doi.org/10.1111/j.0014-3820.2004.tb01678.x

Rambaut, A. \& Drummond, A. J. 2007: Tracer. v. 1.5 Available at http://beast.bio.ed.ac.uk/Tracer.

Roger, A. J. \& Hug, L. A. 2006: The origin and diversification of eukaryotes: Problems with molecular phylogenetics and molecular clock estimation. — Philosophical Transactions of the Royal Society B: Biological Sciences 361(1470): 1039-1054. doi: https://doi.org/ 10.1098/rstb.2006.1845

Tamura, K. 1992: Estimation of the number of nucleotide substitutions when there are strong transition-transversion and $\mathrm{G}+\mathrm{C}$-content biases. - Molecular Biology and Evolution 9: 678-687. doi: https://doi.org/ 10.1093/oxfordjournals.molbev.a040752

Tamura, K., Peterson, D., Peterson, N., Stecher, G., Nei, M. \& Kumar, S. 2011: MEGA5: Molecular evolutionary genetics analysis using maximum likelihood, evolutionary distance, and maximum parsimony methods. - Molecular Biology and Evolution 10: 27319. doi: https://doi.org/10.1093/molbev/msr121 